\title{
The morphology of the afferent and efferent domain of the sheep glomerulus
}

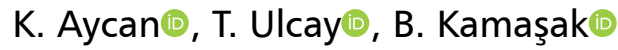 \\ Department of Anatomy, Faculty of Medicine, Kırşehir Ahi Evran University, Kırşehir, Turkey
}

[Received: 9 April 2020; Accepted: 16 September 2020; Early publication date: 12 October 2020]

Background: It is important to know the morphology of the glomerulus in order to explain kidney infiltration. The present study aims to research the morphology of afferent and efferent domains of sheep kidney glomeruli.

Materials and methods: In this study, 2000 glomeruli from 20 kidneys of Akkaraman sheep were examined using the polyester resin method.

Results: It was found that the glomeruli of sheep kidney usually had an afferent arteriole as well as an efferent arteriole. Besides, it was also found that five glomeruli had two efferent arterioles. It is known that the afferent domain constitutes the largest part of the glomerulus. In two of the glomeruli that we examined, the afferent domain formed the 1/2 of the glomeruli wherein the other two glomeruli afferent domain formed the 3/4.

Conclusions: It is known that there are many anastomoses between the afferent and efferent domain of capillaries. However, it is not well-explained how anastomosis is created between the afferent and efferent domains. In our study, it was identified that those anastomoses were not inside the lobes but between the surrounding capillaries. (Folia Morphol 2021; 80, 4: 881-887)

Key words: morphology, sheep glomerulus, afferent arteriole, efferent arteriole

\section{INTRODUCTION}

Kidney is a significant organ which controls homeostasis, water volume and electrolytes in blood, and blood pressure. The foremost function of the kidney is urine filtration. Histologically, the kidney is formed of peripherally situated cortex and a centrally located medulla. The cortex is very rich in nephrons that are considered the main functional unit consisting of the renal corpuscle and renal tubules. On histological specimens, the renal corpuscle looks like a small rounded structure that has a centrally located glomerulus surrounded peripherally by Bowman's capsule. The glomerulus is a collection of capillaries lined and united by a delicate mesangial matrix, while the Bowman's capsule consists of two epithelium layers: visceral (envelops glomerulus) and parietal [12].

It is essential to know the morphology of the glomerulus in order to explain kidney infiltration. In 1666, Malpighi first described the glomeruli and demonstrated their continuity with the renal vasculature [see 20]. About 175 years later, Bowman elucidated in detail the capillary architecture of glomerulus and the continuity between its surrounding capsule and the proximal tubule [3, see 20]. The renal corpucle consist of a tuft of interconnected capillaries and an enclosing capsule named after Bowman. The term "glomerulus" is commonly used refer to glomerular capillary tuft and Bowman's capsule, although the 
term "renal corpucle" is more accurate in a strick ball of capillaries. Providing structural support for the capillary tuft is a central region termed the mesangium, which contains cells and their surrounding matrix material. The capillaries are a thin layer of endotelial cells, contain a basement membran, and are covered by epitelial cells that form the visceral layer of Bowman's capsule. The parietal epithelium is continous with the visceral epithelium at the vascular pole where the afferent arteriole enters the glomerulus and the efferent arteriol exits $[13,20]$.

The human glomerulus average diameter is $200 \mu \mathrm{m}$; juxtaglomedullary glomeruli are $20-50 \%$ greater than superficial glomeruli in mammals $[13,20]$.

Afferent arteriole capillaries entering the Bowman's capsule form the afferent domain via heading towards the urinary pole. These capillaries bend into the urinary pole in a $U$ shape to form an efferent domain. Capillaries of efferent domain merge and form efferent arteriole. Efferent arteriole leaves the glomerulus at the blood vascular pole [10, 23].

The glomerular tuft, originating from afferent arteriole that enters at the vascular pole, separates into lobules. Each lobule has an afferent and efferent domain. The afferent domain of lobules constitutes most of the glomerular tuft. In human and some animals, the glomerular tuft is split into three to eight lobules [11, 20, 23].

The efferent domain is located in the middle of the afferent domain [5, 23]. Glomeruli have an afferent domain and efferent arteriole. In some animals, glomeruli have two afferent or four efferent arterioles $[5,10,14,15]$.

The diameter of the efferent arteriole is smaller than the diameter of the afferent arteriole $[5,7,10,16]$.

There are a few studies investigating sheep kidney glomerulus. These studies did not show the morphology of sheep glomerulus clearly $[1,4,16]$. It is known that there are anastomoses between the capillaries of the afferent and efferent domains. However, it has not been explained how these anastomoses are formed $[6,10,11,17]$. The present study aims to research the morphology of afferent and efferent domains of sheep kidney glomeruli.

\section{MATERIALS AND METHODS}

Twenty sheep kidneys from 10 Akkaraman sheep (12-20 months old and 35-45 kg) were used in this study. Ten mililitres physiological saline containing $2 \%$ heparin was injected into the renal arteries after

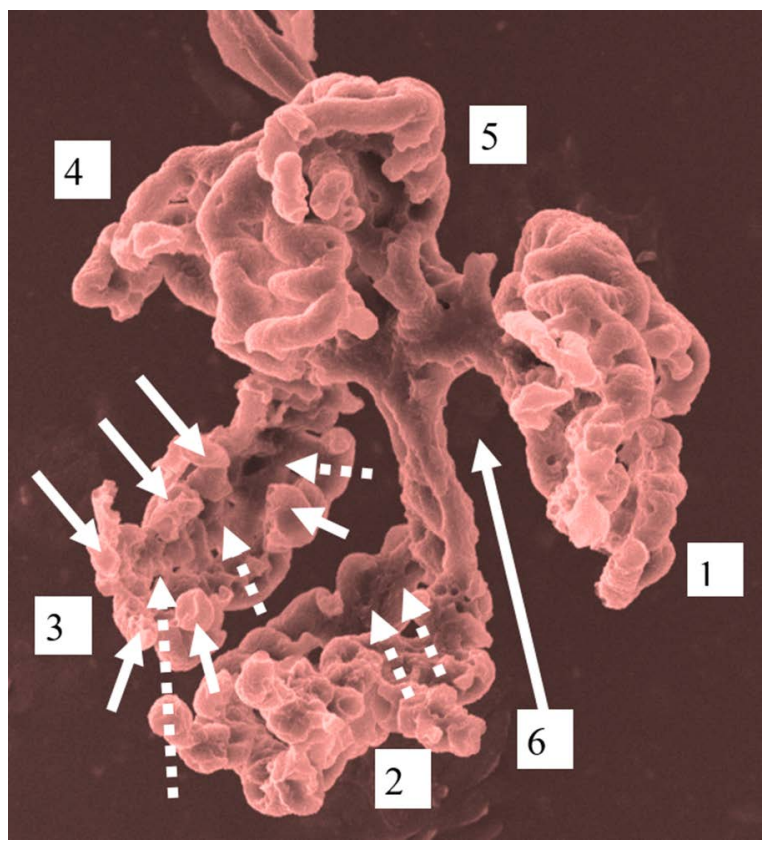

Figure 1. Afferent domain of the sheep. Lobe of the glomerulus (1-5), capillary anastomoses between afferent and efferent domain (white arrow), no capillary anastomoses on the internal surface of the glomerular lobe (dotted arrow), and exit pole of the efferent arteriole (6). Magnification $\times 423$.

cleaning the tissues surrounding the kidney. In order to show the glomeruli, $15 \mathrm{~mL}$ of the polyester resin solution was injected into renal arteries with a 120- $\mathrm{mmHg}$ pressure. Twenty-four hours passed for the solidification of the polyester solution. The kidneys were put into a $37 \% \mathrm{HCL}$ solution for 24 hours. Kidney tissues that were dissolved were washed under tap water and air-dried. With the use of a stereomicroscope, glomeruli with afferent and efferent domains were dissected with a forceps from the blood vessels of the kidneys (2000 glomeruli were analysed on average) $[2,16,22]$. Isolated glomeruli were placed on metal plates, and then they were covered with gold in a vacuum evaporator (Polaron 7650 Mini Sputter Coater). They were studied with a scanning electron microscope (LEO 440).

\section{RESULTS}

In this study, the afferent and efferent domains of sheep glomeruli were investigated using the polyester resin method. The morphology of sheep kidney glomeruli was shown well with this method.

All of the sheep glomeruli studied had an afferent and efferent arteriole (Figs. 1-7). Glomeruli of sheep kidneys usually had five lobules (Figs. 1, 7). 


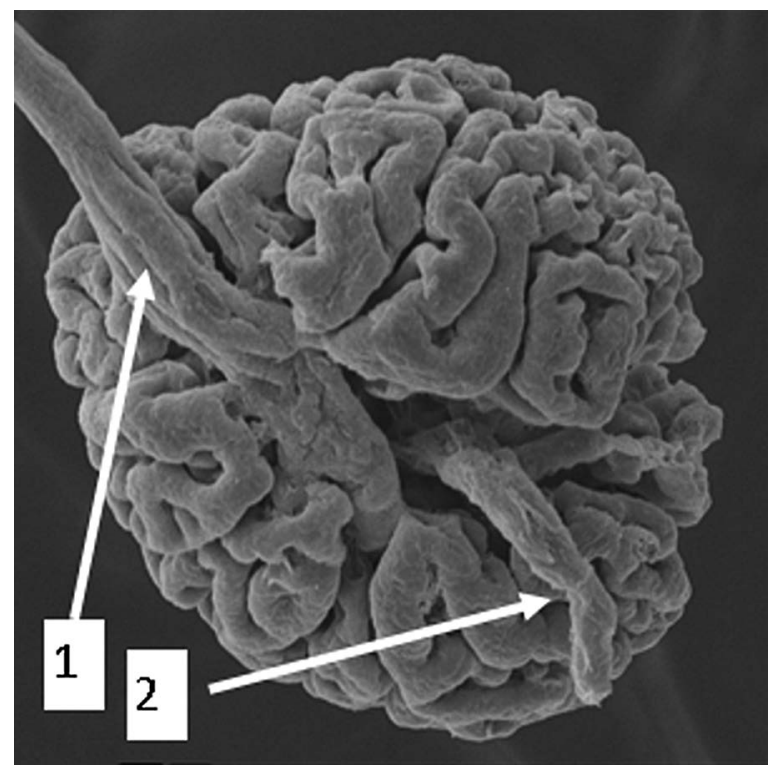

Figure 2. Glomerulus of the sheep. Afferent arteriole (1), efferent arteriole (2). External view shows gyri of the cerebrum. Magnification $\times 515$.

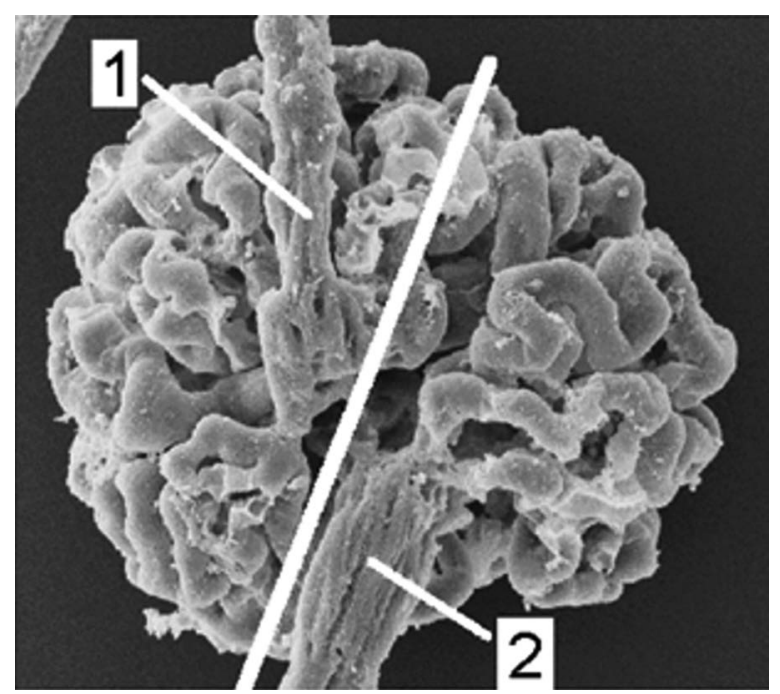

Figure 3. Afferent and efferent domain covers $1 / 2$ of the glomerular tuft; 1 - afferent arteriole; 2 - efferent arteriole. Magnification $\times 41$.

Branches of afferent arterioles formed a ring-like cavity in the blood vascular pole of the glomerulus. Efferent arterioles that were formed by merged capillaries of the efferent domain came through this cavity (Figs. 1, 2, 5, 8).

The capillaries of the efferent arteriole joined at the vascular pole to form an efferent arteriole. Sometimes in the case of a failure of this joining, the glomerulus might have two efferent arterioles. In this

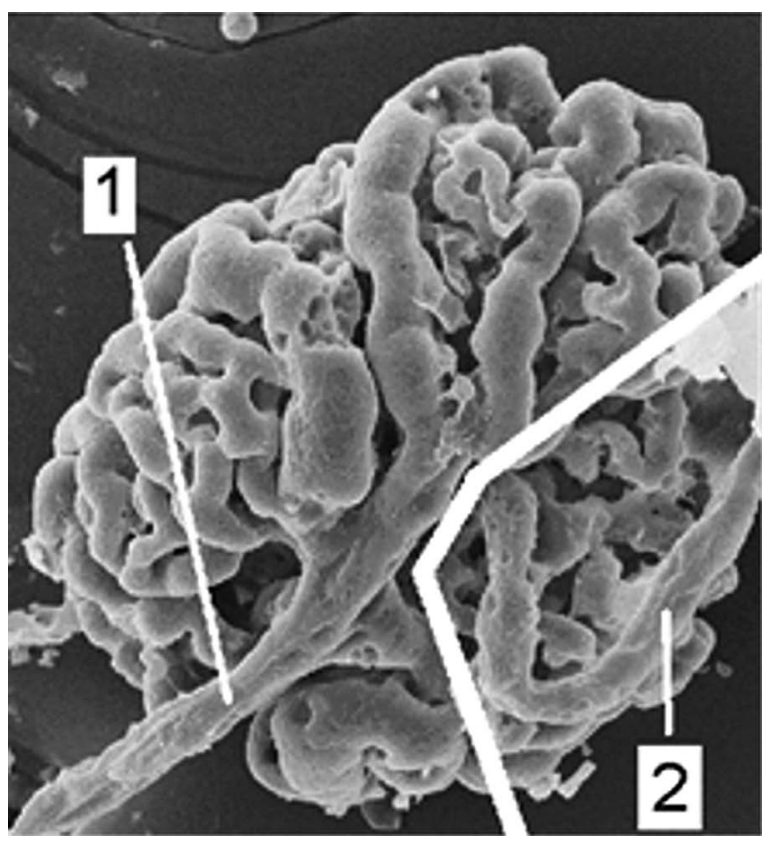

Figure 4. Afferent domain covers $3 / 4$ of the glomerular tuft; 1 afferent arteriole (domain); 2 - efferent arteriole (domain). Magnification $\times 436$.

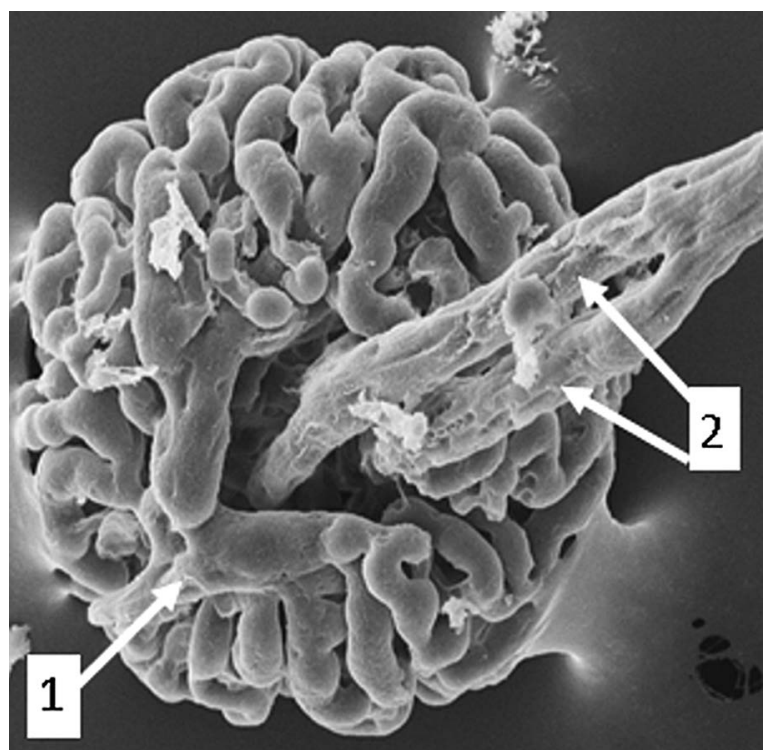

Figure 5. Two roots of the efferent arteriole are merged out of the glomerulus; 1 - afferent arteriole; 2 - efferent arteriole. Magnification $\times 370$.

study, five glomeruli having two efferent arterioles $(5 / 2000)$ were observed (Figs. 5, 6) Although the afferent domain constituted most of the glomerular tuft, it was identified that the afferent domain formed $3 / 4$ of the glomerulus in two cases and 1/2 of the glomerulus in two other cases (Figs. 3, 4). 


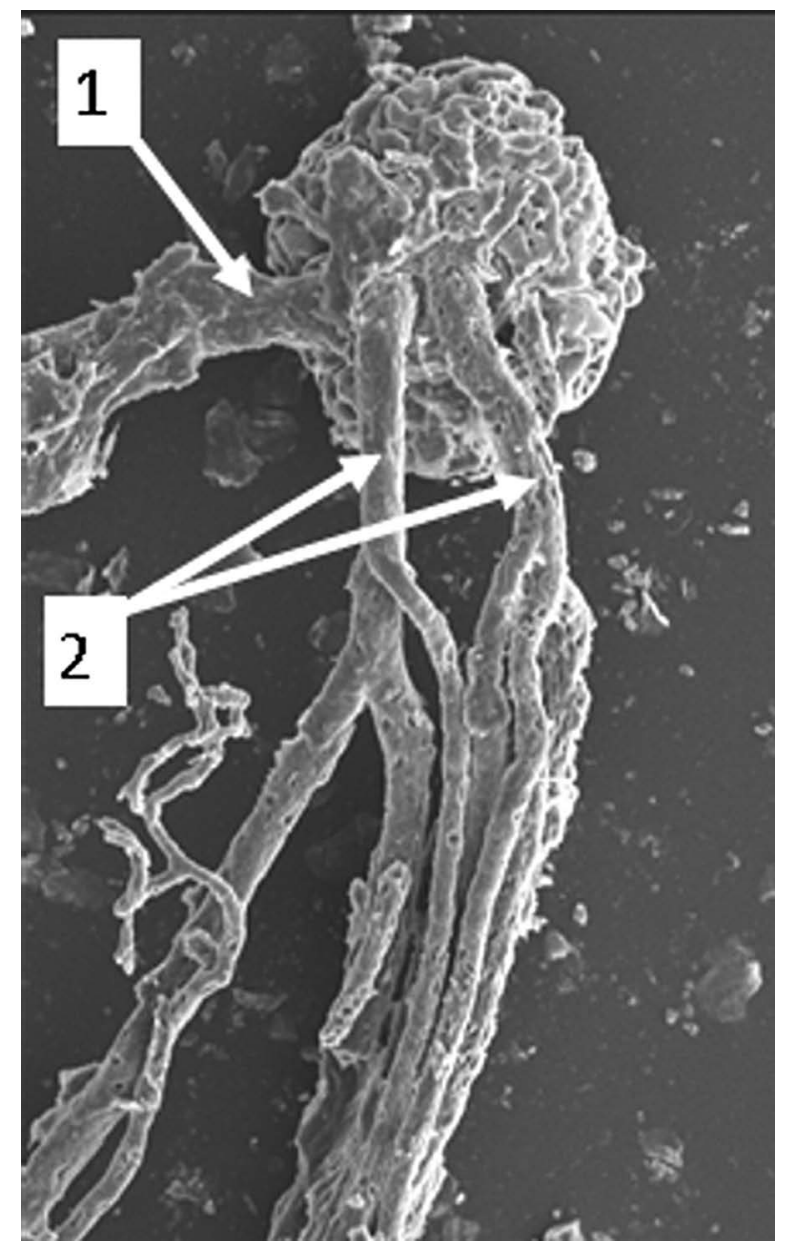

Figure 6. Five sheep glomeruli have two efferent arterioles; $1-$ afferent arteriole; $2-$ efferent arteriole. Magnification $\times 50$.

The outer surface of each lobule of sheep glomerulus was convex, whereas the inner surface was concave. The efferent domain resided in the flat inner surface of the lobule (Figs. 2, 5). Anastomoses that were between the afferent domain arterioles showed protrusions that were similar to the gyri of the brain. Some of these structures resembled the letters $\mathrm{U}, \mathrm{O}, \mathrm{S}, \mathrm{J}$, and $\mathrm{H}$. There were holes inside the cavities between those protrusions (Figs. 9, 10).

Anastomoses that were located between the capillaries of the afferent and efferent domains existed around the lobule. There were no capillary anastomoses inside the lobule (Figs. 1, 8).

The average diameter of all glomerular capillary tufts was $139.5 \mu \mathrm{m}$, the average value for afferent arterioles was $12.08 \mu \mathrm{m}$, and the same value for efferent arteriole was $11.18 \mu \mathrm{m}$. The diameter of the afferent arterioles was greater than the diameter of the efferent arterioles.

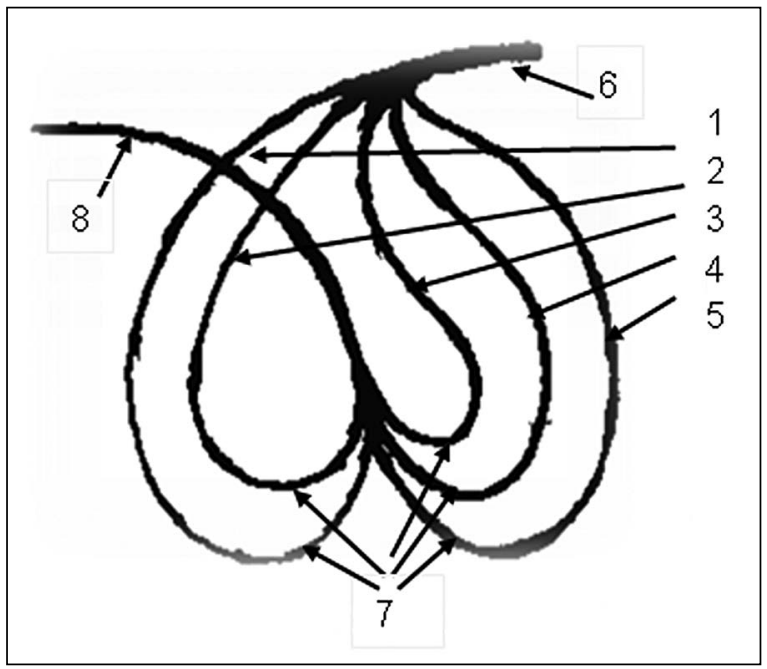

Figure 7. Schematic view of the glomerular lobe; $1,2,3,4,5-$ afferent domain and afferent arteriole divided in five lobes; 6 afferent arteriole; 7 - efferent domain; 8 - efferent arteriole.

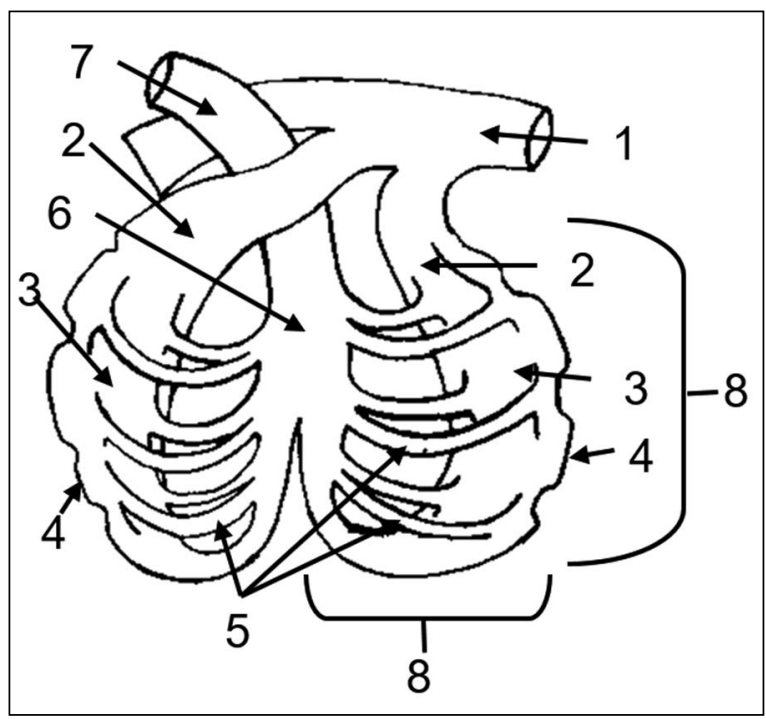

Figure 8. Schematic view of a lobe of glomerular microvasculature; 1 - afferent arteriole; 2 - afferent domain; 3 - internal surface of the glomerular lobule (hollow in shape) (there is no capillary anastomoses between afferent and efferent arterioles in here); 4 - capillary enlargement of the afferent domain in gyrus shape; 5 - capillary anastomoses between afferent and efferent domain; 6 - efferent domain; 7 - efferent arteriole; 8 - one lobe of glomerulus.

\section{DISCUSSION}

Knowledge of glomerulus morphology is of great importance in explaining kidney infiltration. Therefore, the afferent and efferent domains of the glomerular tuft have been studied with different methods for years $[5-8,10,11,15,17,18,23]$. The renal glomeruli 

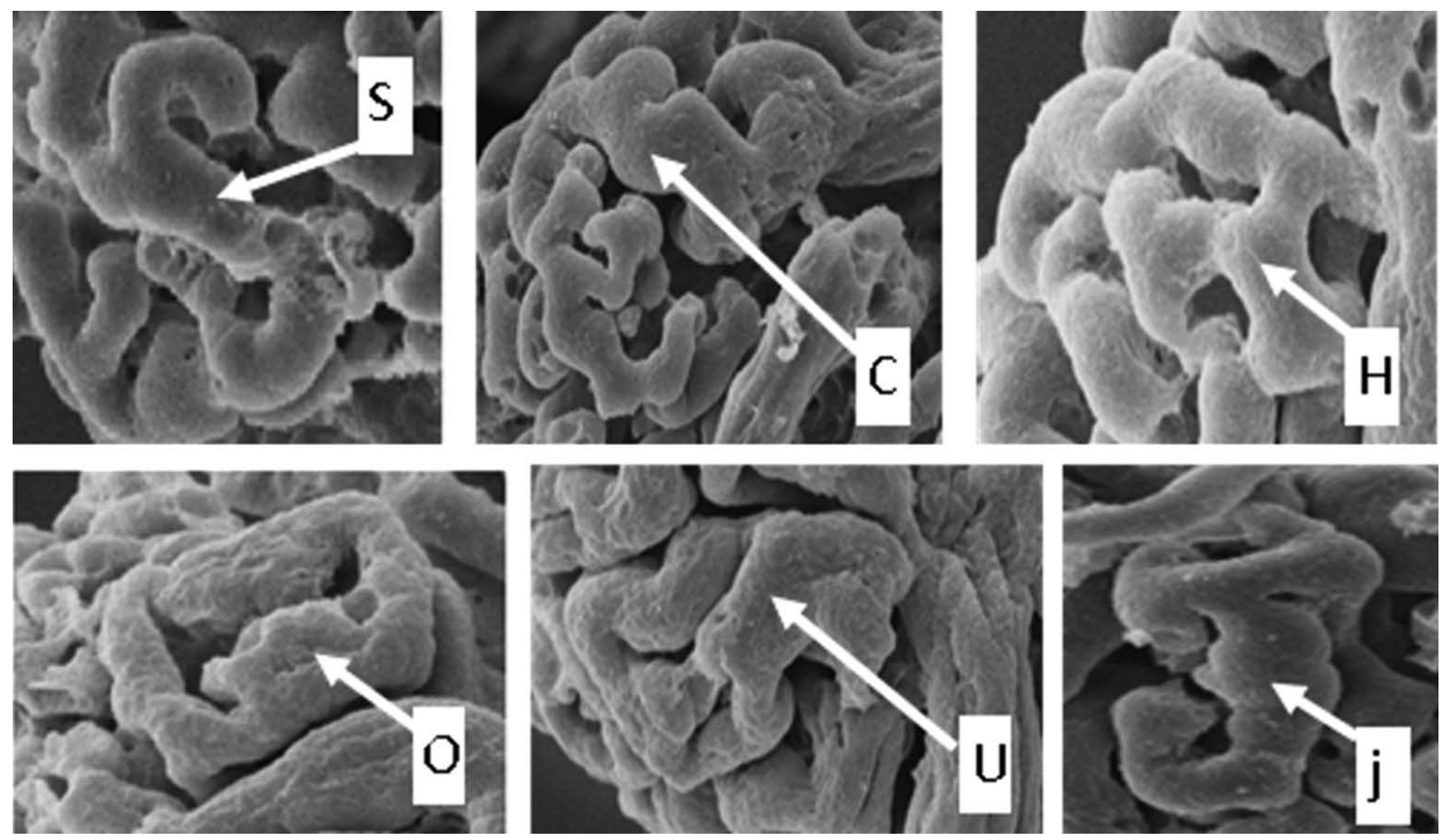

Figure 9. Capillary enlargement of the of external surface of afferent domain $(\mathrm{S}, \mathrm{C}, \mathrm{H}, \mathrm{O}, \mathrm{U}$, and $\mathrm{J}$ shape).

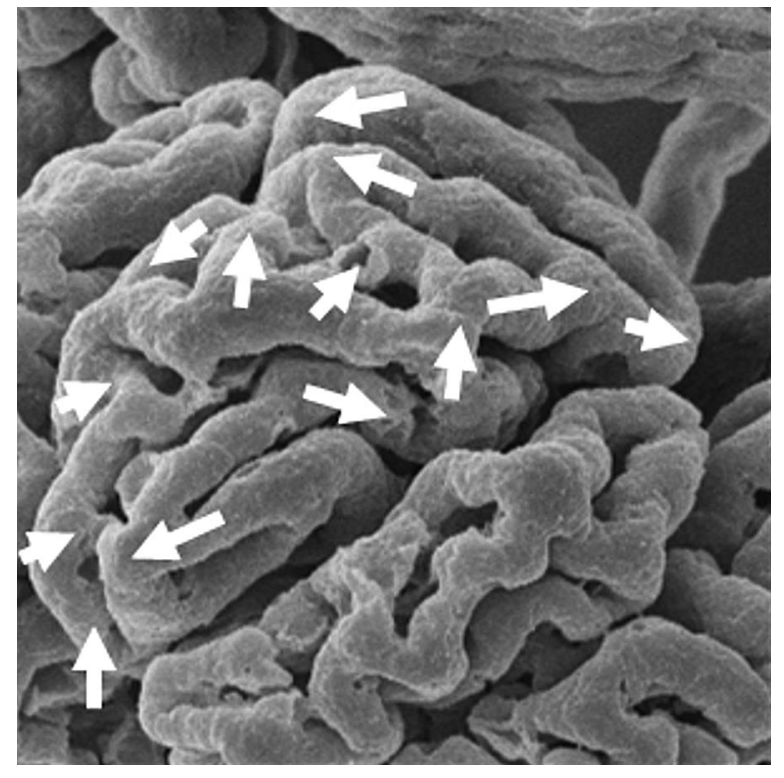

Figure 10. Capillary anastomoses in one lobule of the afferent domain (white arrow).

of the sheep have not been explained yet by corrosion casting method. The glomerulus is located in the cortex of the kidney. The cortex is composed of three parts: outer, middle, and inner cortex. In this study, the middle and outer cortex of 2000 sheep kidney glomeruli were examined [9]. It is known that afferent arterioles originate from interlobular arteries [1]; the sheep glomerulus afferent arterioles also originated from interlobular arteries in our study. In our study, afferent arteriole separated into five branches that entered the Bowman's capsule. Every branch of afferent arterioles constitute a lobule of glomerulus. Glomeruli of sheep kidneys usually have five lobules (Figs. 1, 7). Every lobule has an afferent domain and efferent domain. Every efferent domain capillary is merged with each other to constitute efferent arteriole. Capillaries of every lobule anastomose with each other; this capillary do not anastomose with the other capillary of the lobule.

Recent studies indicate that mouse, rabbit, dog, sheep, and human glomeruli have two to eight lobules [11, 20, 23]. In our study, it was observed that sheep glomeruli had five lobules (Figs. 1, 7). Human glomerulus in health and disease comprises seven lobule-like structures with numerous anastomoses, but there are no direct anastomoses between the afferent and efferent arterioles [4]. In our study, Akkaraman sheep glomerulus comprised five lobules. Every lobuls has afferent and efferent domain. This domain of lobule do not anastomose with other lobules. There are direct anastomoses between this domain's arterioles. 
Recent studies and our study showed that the afferent domain composed most of each lobule or outer surface of the glomerular tuft. The efferent domain resides in the middle of the afferent domain [23]. Although the same cases were observed in our study, it also indicated that the afferent domain formed $3 / 4$ of the glomerular tuft, whereas in the other two cases the afferent domain constituted $1 / 2$ of the glomerular tuft (Figs. 3, 4).

Various studies show that each glomerulus has one afferent arteriole. It was found in our study that all sheep glomeruli had one afferent arteriole. However, some investigations shows that there are two or four afferent arterioles in a glomerulus. One of these feeds two lobules, whereas the other one feeds three lobules $[5,10,15]$.

It is known that the efferent domains merge and form an efferent arteriole in the glomerulus. Sometimes when the merging fails, two or four efferent arterioles exist $[5,10,18,22]$. Five glomeruli were identified in our study having two efferent arterioles (Figs. 5, 6).

Our investigations found sheep glomeruli average diameter to be $139.5 \mu \mathrm{m}$. The lomerulus average diameter was $200 \mu \mathrm{m}$. Juxtaglomedullary glomeruli are $20-50 \%$ greater than superficial glomeruli in mammals; others have found no significant size difference between these glomerular population in the normal human adult kidney $[13,20]$.

The calibres of the afferent and efferent arterioles of the glomeruli appear in the casts to be about the same. In the human juxtaglomedullary glomeruli the afferent and efferent arterioles are of equal calibre, while in the cortical glomeruli the efferent arterioles are much narrower than the afferent [21]. In the fowl, arterioles of both cortical and juxtaglomedullary glomeruli appear to be equal in diameter [19].

As in recent animal research, the diameter of the efferent arteriole is smaller than the diameter of the afferent arteriole $[5,7,10,16]$. In the sheep, the diameter of the afferent arteriole was greater than that of the efferent arteriole [1]. In our study afferent arteriole diameter was $12.08 \mu \mathrm{m}$, efferent arteriole dimeter was $11.18 \mu \mathrm{m}$. The smaller diameter of efferent arteriole has great importance in infiltration [16].

The total length of the capillaries in a single glomerulus is $0.95 \mathrm{~cm}$. The total surface area of all glomerular capillaries is $6,000 \mathrm{~cm}^{2}$ [4]. We have not measured the total length or total surface area of the capillaries in a single glomerulus.
Protrusions like the gyri of the brain were observed on the outer surface of afferent domain capillaries in our research (Fig. 9). It is understood that those protrusions are the anastomoses located between the capillaries. These structures that are formed by afferent domain resemble letters $\mathrm{U}, \mathrm{O}, \mathrm{S}, \mathrm{J}$, and $\mathrm{H}$ (Figs. 9, 10). This suggests that these protrusions have an essential role in infiltration.

\section{CONCLUSIONS}

The morphology of sheep kidney glomeruli is well shown with corrosion method. The afferent arteriole separated into five branches enter the Bowman's capsule in sheep glomeruli. Every branch of afferent arterioles constitutes a lobule of glomerulus. Glomeruli of sheep kidneys usually have five lobules. Every lobule has an afferent domain and efferent domain. Every efferent domain capillary is merged with each other to constitute efferent arteriole. Capillaries of every lobule anastomose with each other; this capillary do not anastomose with the other capillary of lobule. Anastomoses that are located between the capillaries of the afferent and efferent domains exist around the lobule. There are no capillary anastomoses inside the lobule. There are holes inside the cavities of lobule.

The efferent domain resides in the flat inner surface of the lobule. The capillaries of the efferent arteriole join at the vascular pole to form an efferent arteriole. All of the sheep glomeruli have an afferent and efferent arteriole. Sometimes sheep glomerulus might have two efferent arterioles.

The diameter of the afferent arterioles is greater than the diameter of the efferent arterioles. Anastomoses that are between the afferent domain arterioles show protrusions that are similar to the gyri of the brain. Some of these structures resemble the letters $\mathrm{U}, \mathrm{O}, \mathrm{S}, \mathrm{J}$, and $\mathrm{H}$.

It is believed that the present study has a vital role in revealing the morphology of human or mammal glomeruli.

Conflict of interest: None declared

\section{REFERENCES}

1. Anderson B, Anderson W, Seguin R. Renal microvasculature of the black bear (Ursus americanus). Cells Tissues Organs. 1988; 132(2): 124-131, doi: 10.1159/000146563.

2. Aycan K, Bilge A. Plastik enjeksiyon ve korrozyon metodu ile vasküler sistem anatomisinin Araştırılması. Erciyes Üniv Tıp Fak Dergisi. 1984; 6: 545-552. 
3. Bellomo G. A short history of 'glomerulus'. Clin Kidney J. 2013; 6(2): 250-251, doi: 10.1093/ckj/sft022, indexed in Pubmed: 26019863.

4. Bohle A, Aeikens B, Eenboom A, et al. Human glomerular structure under normal conditions and in isolated glomerular disease. Kidney Int Suppl. 1998; 67: S186-S188, doi: 10.1046/j.1523-1755.1998.06742.x, indexed in Pubmed: 9736285.

5. Brown JA. Renal microvasculature of the rainbow trout, Salmo gairdneri: scanning electron microscopy of corrosion casts of glomeruli. Anat Rec. 1985; 213(4): 505-513, doi: 10.1002/ar.1092130405, indexed in Pubmed: 4083531.

6. Casellas D, Mimran A. Aglomerular pathways in intrarenal microvasculature of aged rats. Am J Anat. 1979; 156(2): 293-299, doi: 10.1002/aja.1001560209, indexed in Pubmed: 506956.

7. Casotti G, Braun EJ. Structure of the glomerular capillaries of the domestic chicken and desert quail. J Morphol. 1995; 224(1): 57-63, doi: 10.1002/jmor.1052240107, indexed in Pubmed: 7723047.

8. Elger M, Sakai T, Kriz W. The vascular pole of the renal glomerulus of rat. Adv Anat Embryol Cell Biol. 1998; 139: 1-98, doi: 10.1007/978-3-642-80449-6, indexed in Pubmed: 9386305.

9. Evan AP, Dail WG. Efferent arterioles in the cortex of the rat kidney. Anat Rec. 1977; 187(2): 135-145, doi: 10.1002/ ar.1091870202, indexed in Pubmed: 848773.

10. Frank M, Kriz W. Scanning electron microscopy studies of the vascular pole of the rat glomerulus. Anat Rec. 1982; 204(2): 149-152, doi: 10.1002/ar.1092040208, indexed in Pubmed: 7181131.

11. Kazimierczak J. A study of scanning (SEM) and transmission (TEM) electron microscopy of the glomerular capillaries in developing rat kidney. Cell Tissue Res. 1980; 212(2): 241-255, doi: 10.1007/BF00233959, indexed in Pubmed: 7428030.

12. Kotyk T, Dey N, Ashour AS, et al. Measurement of glomerulus diameter and Bowman's space width of renal albino rats. Comput Methods Programs Biomed. 2016; 126: 143-153, doi: 10.1016/j.cmpb.2015.10.023, indexed in Pubmed: 26796351.
13. Mills SE. Histology for patologists. Fourth edition. Wolters Kluwer/Liicott/Philadelphia, PA: Liincott Williams and Wilkins., Philadelphia-London 2012: 928-938.

14. Murakami T. Double afferent arterioles of the rat renal glomerulus as studied by the injection replica scanning electron microscopic method. Arch Histol Jpn. 1976; 39(5): 327-332, doi: 10.1679/aohc1950.39.327, indexed in Pubmed: 1021016.

15. Murakami T, Kikuta A, Akita S, et al. Multiple efferent arterioles of the human kidney glomerulus as observed by scanning electron microscopy of vascular casts. Arch Histol Jpn. 1985; 48(4): 443-447, doi: 10.1679/aohc.48.443, indexed in Pubmed: 4084007.

16. Oguz O, Dere F, Yücel AH, et al. Examination of microvascular structures of midcortical region in sheep kidneys: a three dimensional approach. Acta Med Okayama. 1991; 45(2): 77-80, doi: 10.18926/AMO/32185, indexed in Pubmed: 1867114.

17. Oguz O, Dere $F$, Yücel $A H$, et al. Scanning electron microscopic (SEM) examination of structures which supply subcapsular and midcortical region postglomerular microcirculation in sheep kidney. Acta Morphol Hung. 1992; 40(1-4): 195-202, indexed in Pubmed: 1365763.

18. Rovenská E. Two types of capillaries in the rat renal glomerulus. Acta Anat (Basel). 1983; 115(1): 31-39, indexed in Pubmed: 6829268.

19. Siller WG, Hindle RM. The arterial blood supply to the kidney of the fowl. J Anat. 1969; 104(Pt 1): 117-135, indexed in Pubmed: 5761744.

20. Sternberg SS. Histology for pathologists. 2nd ed. Lippincott-Raven Publishers, Philadelphia 1997.

21. Trueta J, Barclay AE, Daniel PM. Studies of the Renal Circulation. Blackwell Scientific Publications, Oxford 1947.

22. Tsikaras PD, Hytiroglou PM, Lazos LM. The use of unsaturated polyester resin solutions in preparing casts of the renal vessels. Bull Assoc Anat (Nancy). 1985; 69(204): 71-78, indexed in Pubmed: 3833313.

23. Winkler D, Elger M, Sakai T, et al. Branching and confluence pattern of glomerular arterioles in the rat. Kidney Int Suppl. 1991; 32: S2-S8, indexed in Pubmed: 1881043. 